\title{
Neural Mechanisms in Eating Behaviors: A Pilot fMRI Study of Emotional Processing
}

\author{
Rosa M. Molina-Ruiz ${ }^{\bowtie}$, T. García-Saiz², Jeffrey C.L. Looi ${ }^{3}$, E. Via Virgili4 ${ }^{4}$ M. Rincón Zamorano², \\ Laura de Anta Tejado', Helena Trebbau López ${ }^{1}$, Jose Luis Carrasco Perera', and Marina Díaz-Marsá1 \\ ${ }^{1}$ Psychiatry Department, Universitary Hospital Clinico San Carlos of Madrid, IddISC, Madrid, Spain \\ ${ }^{2}$ Artificial Intelligence Department, UNED. E.T.S.I. Informatics, Madrid, Spain \\ ${ }^{3}$ Academic Unit of Psychiatry and Addiction Medicine, Australian National University Medical School, Canberra Hospital, Canberra, Australia \\ ${ }^{4}$ Hospital Materno-Infantil Sant Joan de Déu, Barcelona, Spain
}

Objective Emotional processing dysfunction evident in eating disorders (ED) such as anorexia nervosa (AN) and bulimia nervosa $(\mathrm{BN})$, is considered relevant to the development and maintenance of these disorders. The purpose of the current functional magnetic resonance imaging (fMRI) study was to pilot a comparison of the activity of the fronto-limbic and fronto-striatal brain areas during an emotion processing task in persons with ED.

Methods 24 women patients with ED were scanned, while showing emotionally stimulating (pleasant, unpleasant) and neutral images from the International Affective Picture System (IAPS).

Results During the pleasant condition, significant differences in Dorsolateral Prefrontal Cortex (DLPFC) activations were found with AN participants presenting greater activation compared to $\mathrm{BN}$ and $\mathrm{ED}$ comorbid groups (EDc) and healthy controls also showing greater activation of this brain area compared to BN and EDc. Left putamen was less activated in EDc compared to both controls (C) and AN. During the unpleasant condition, AN participants showed hyperactivation of the Orbito-Frontal Cortex (OFC) when compared to EDc.

Conclusion This study highlights the potential functional relevance of brain areas that have been associated with self-control. These findings should help advance understanding the neural substrate of ED, though they should be considered as preliminary and be cautiously interpreted.

Psychiatry Investig 2020;17(3):225-236

Key Words Functional magnetic resonance imaging, Eating disorders, Emotion processing, Prefrontal cortex, Striatum.

\section{INTRODUCTION}

Recent studies in eating disorders (ED) have found evidence of emotional awareness and emotion processing alterations in ED. ${ }^{1-5}$ However, the current literature is not sufficiently informative regarding the nature of emotional processing in ED to develop a model on which to base therapeutic interventions. Emotional processes currently identified in ED implicate amygdalo-cortical and cortico-striato-thalamo-cortical re-entrant circuits $^{6-10}$ in creating dysregulated appetitive be-

Received: April 4, 2019 Revised: June 22, 2019

Accepted: October 14, 2019

$\triangle$ Correspondence: Rosa M. Molina-Ruiz, MD, PhD

Psychiatry Department, Universitary Hospital Clínico San Carlos de Madrid, Madrid, IddISC, Spain

Tel: +34-676106633, E-mail: rosamolina18@hotmail.com

(c) This is an Open Access article distributed under the terms of the Creative Commons Attribution Non-Commercial License (https://creativecommons.org/licenses/bync/4.0) which permits unrestricted non-commercial use, distribution, and reproduction in any medium, provided the original work is properly cited. haviours (e.g., food restriction, vomiting) in $\mathrm{ED} .{ }^{11}$

Based upon current studies of emotional processing in ED, persons with anorexia nervosa (AN) may present with exaggerated cognitive control and seek to reduce negative emotions and anxiety symptoms by restricting food; while those with bulimia nervosa (BN) may have deficient cognitive control, thus increasing the instability and erratic responding to appetitive stimuli and obtaining a reduction of negative emotions with binge eating and purging. ${ }^{12,13}$ Such impulsive eating behaviours are more frequently seen in EDs associated with borderline personality traits. ${ }^{14-18}$ Based on this cognitive-control model, extremes of eating behaviour would emerge from an altered balance of reward and inhibitory processing. ${ }^{10}$ Consequently this model for ED could be understood across an impulsive-compulsive spectrum: from obsessive disorders, with a greater tendency to harm avoidance and compulsive behaviours at the compulsive end (AN restrictive) in contrast to those with high impulsivity, with a tendency towards harm 
avoidance- $\mathrm{AN}$ binge-purging, $\mathrm{BN}$ and borderline personality disorder (BPD)-. ${ }^{10,19-22}$ Regarding brain functioning, corticostriatal circuit dysfunction may be implicated in suppressing or inhibiting inappropriate behaviours that underpin impulsive and compulsive symptomatology in obsessive-compulsive disorders ${ }^{22-24}$ and also in emotional processing and regulation processes, ${ }^{25-27}$ and therefore they may be of interest in the study of ED.

Neuroimaging techniques offer a window into the activity of neuronal circuits involved in emotional processing in ED. ${ }^{28-30}$ These functional MRI (fMRI) studies in ED have used body images or food paradigms as aversive stimuli mainly. ${ }^{31-40}$ However, the paradigms and methodologies used in these studies vary greatly, making it difficult to draw coherent conclusions. Moreover, compared to these previous paradigms, the use of general emotional stimuli may allow better understanding of emotional processing in general in EDs, since emotional processing is considered a core symptom related to eating behaviours (i.e., restricting, purging) and it might not be only a consequence of food or body shape. From this point of view the International Affective Picture System (IAPS), ${ }^{41}$ which consist of a well-characterized collection of visual coloured images designed to evoke either neutral, positive or negative emotional states, seems a suitable tool. To our knowledge, although some studies have used IAPS to test the emotional reactivity of ED patients to social situations, ${ }^{42}$ no previous fMRI emotional processing studies in ED have focused on general, as opposed to disease-specific, emotional stimuli. fMRI studies in healthy persons have identified brain networks involved in emotion processing mechanisms, a number of them employing images from the IAPS. ${ }^{41}$ In healthy individuals, viewing of emotional pictures is associated with activation in prefrontal cortex areas (dorsolateral, ventromedial and orbitofrontal), ${ }^{43-46}$ amygdalahippocampal regions ${ }^{44,45}$ and basal ganglia, ${ }^{44}$ among others.

The purpose of the present study was to explore the general emotional processing in ED, through using a small subset of complex visual scenes (depicting happiness, fear, anger, or threat), derived from the IAPS as stimuli. ${ }^{41}$ Based on the above previous studies, we hypothesized that AN patients may be able to inhibit appetite and exert extraordinary self-control because of exaggerated cortico-amygdalar and cortico-striatal circuit function (hyperactivation); whereas individuals with $\mathrm{BN}$ may be more vulnerable to overeating because they have less top down regulation, i.e., self-control, probably due to a lower activation of cortico-amygdalar and cortico-striatal circuits (hypoactivation) when presented with emotional eliciting cues (Figure 1). On the other hand, a high prevalence of borderline personality disorder has been reported in $\mathrm{BN}$ and purgative $\mathrm{AN},{ }^{16}$ which sometimes might complicate the differential diagnosis and have BPD-associated hypofunction of

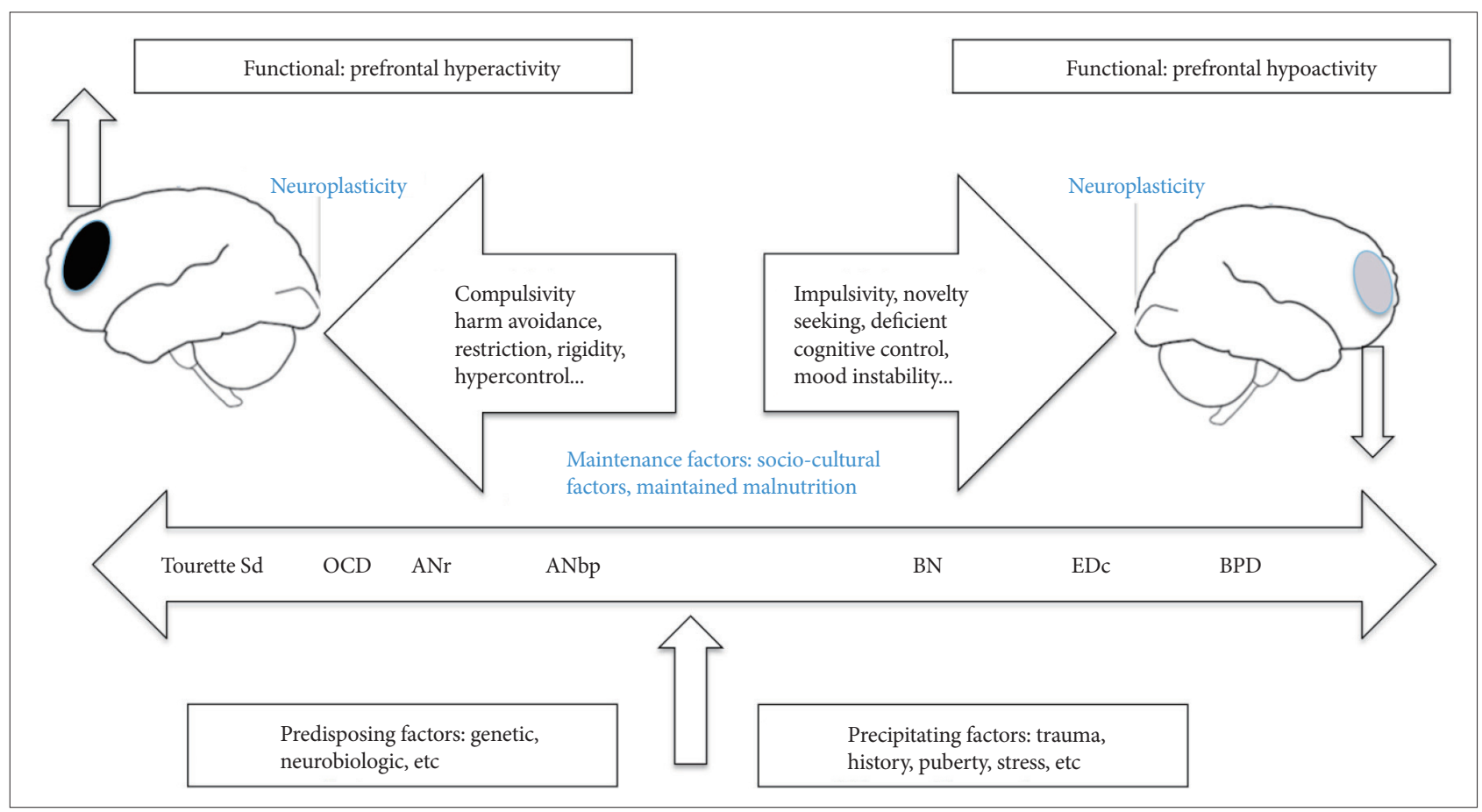

Figure 1. Diagram of impulsive-compulsive spectrum disorders. On the left: "compulsive end," mainly represented by disorders where obsessions and compulsions are prominent (AN, OCD, Tourette Sd: Tourette's Syndrome). On the right: "impulsive end," where impulsivity plays a crucial role (e.g., BN, EDc, and BPD). ${ }^{20}$ Tourette Sd: Tourette's Syndrome, OCD: Obsessive Compulsive Disorder, ANr: restrictive Anorexia Nervosa, ANbp: binge purging type Anorexia Nervosa, BN: Bulimia Nervosa, EDc: Eating Disorder with comorbid with borderline personality disorder. 
regions of prefrontal cortex. ${ }^{47}$ A subgroup study of $\mathrm{ED}$ with BPD comorbidity was performed to differentiate from the other pure $\mathrm{ED}$ groups.

\section{METHODS}

\section{Subjects}

Twenty-four female patients diagnosed with either AN $(\mathrm{n}=8), \mathrm{BN}(\mathrm{n}=9)$, or eating disorder comorbid with borderline personality disorder, $\mathrm{ED}+\mathrm{BPD}(\mathrm{EDc})(\mathrm{n}=7)$ were recruited. Patients with EDc had comorbid diagnoses of BPD and $\mathrm{BN}$. All of them were current outpatients at a major teaching Hospital in Madrid (Spain), were stable (had not had any hospitalization during the last year and were on regular ambulatory treatment), had similar sociodemographic characteristics and were receiving regular ambulatory treatment (all of them were receiving Cognitive Behavioural Therapy, and might be taking SSRI or benzodiazepines). None of them had been taking antipsychotics for the last 6 months.

Diagnoses were made by experienced psychiatrists (M.D.M; R.M.M.R) according to DSM-IV-TR criteria ${ }^{48}$ clinical diagnostic subtyping was made on the basis of current symptoms at the time of the study.

A control group of healthy females, $C(n=19)$, were recruited by advertisement at University Complutense of Madrid and Hospital Clínico San Carlos, Madrid. They were of the same age range, education and socioeconomic level.

All patients and controls were interviewed by means of the Structured Clinical Interview for DSM-IV (SCID-I and II) ${ }^{49}$ to evaluate Axis I and Axis II diagnosis, and to exclude comorbid Axis I mental disorders in the ED groups. Comprehensive assessments were undertaken to exclude any potential major medical disease such as a history of head trauma, neurological disease, substance use disorders or any other major medical illnesses. We also ensured that controls had no history of ED or any current of past Axis I or Axis II disorder.

Ethical approval for the study was obtained at Hospital Clínico San Carlos, Madrid Clinical Ethics Committee (E-07/121). Written informed consent was provided by all participants.

Impulsivity and bulimic eating behaviors were assessed using both self-report questionnaire measures: 1) impulsivity was assessed with the Barratt impulsiveness Scale (BIS) ${ }^{50,51} \mathrm{a}$ 30-item questionnaire describing common impulsive or non-impulsive (for reverse scored ítems) behaviors and preferences. Items are scored on a 4-point scale: rarely/never=1, occasionally $=2$, often $=3$, almost always/always $=4$. The BIS is one of the most commonly administered self-report measures for the assessment of impulsiveness in both research and clinical settings. For the behavioural assessment of impulsivity, we focused on the general punctuation scale. 2)
Bulimic behaviors were assessed with a self-rating scale, the Bulimic Investigatory Test, Edinburgh (BITE) for the detection and description of binge eating. ${ }^{52,53}$ BITE is a 33-item self-report measure designed to identify individuals with symptoms of bulimia or binge eating. It consists of two subscales: the symptom scale (BITE-sas), which measures the degree of symptoms present, and the severity scale (BITE-ss), which provides an index of the severity of binging and purging behavior as defined by their frequency.

\section{Procedures}

\section{Imaging acquisition}

BOLD functional images were obtained for all participants on a 1.5T General Electric Sigma MRI scanner (GE, Milwaukee, WI, USA) [repetition time (TR)/echo time (TE) $=3,000 / 50$ $\mathrm{ms}$, field of view $(\mathrm{FOV})=22 \times 22 \mathrm{~cm}, 64 \times 64$ pixel matrix, 20 axial slices per scan, slice thickness $=5 \mathrm{~mm}$, gap $=1.5 \mathrm{~mm}$ ].

A total of 204 whole brain volumes were acquired for each run. The first two scans were discarded from analysis to allow magnetic saturation effects. All scanning parameters were selected to optimize the quality of the BOLD signal while maintaining a sufficient number of slices to acquire whole-brain data. Stimuli were presented via a back-projection system.

\section{Experimental paradigm}

The paradigm consisted of two sequences of alternating blocks with experimental conditions that involved the presentation of "emotionally stimulating" versus neutral images from the IAPS (pleasant-neutral and unpleasant-neutral sequences). IAPS includes a standardized and well-characterized collection of visual coloured images designed to evoke either neutral, positive or negative emotional states. ${ }^{54}$ Twenty unpleasant pictures selected from the IAPS, consisted of negative-emotionally evocative images, e.g., injured people, snakes or spiders; while other 20 pleasant pictures were selected from IAPS and consisted of positive-emotion evoking images, e.g., images of happy couples and family or nice landscapes. Finally 20 neutral-valenced pictures were selected to show daily-life objects such as chairs, books or tables.

Each sequence consisted of a total of 7 blocks ( 3 stimulating blocks interleaved into 4 neutral control blocks). Each experimental block consisted of 7 stimuli sequentially presented for 3 seconds. The order of the stimuli was counterbalanced across participants. The paradigm was repeated twice for each participant.

Subjects rested supine in the scanner while viewing the images and were instructed to keep their eyes open to watch all images and to allow themselves to "feel whatever emotion the slides produced." During the rest condition, 30 seconds before 
the first image block and between each positive and negative image block, the patient was told to "relax" (Figure 2).

\section{Image pre-processing and data analyses}

We performed image processing and statistical analyses fMRI data using the FMRIB Software Library (F.S.L.) version 4.1.9 (FMRIB, Oxford, Oxfordshire, UK). Image pre-processing included motion correction, slice timing correction, normalization to the MNI 152 standard space, and spatial smoothing with a $10 \mathrm{~mm}$ full width at half maximum (FWHM). Voxel size after the reconstruction was $2 \times 2 \times 2 \mathrm{~mm}^{3}$.

\section{Statistics}

We analyzed the data using SPSS 15.0 (SPSS Inc., Chicago, IL, USA). Descriptive statistics were used to report the frequencies for the categorical variables and the mean value with the standard deviation (SD) for the continuous variables. Unpaired ANOVA and T-test were used to evaluate the differences among differente groups. To analyse the images, we performed planned three-stage statistical analyses:

1) In the first stage, we obtained the mean response for each subject to the pleasant and unpleasant paradigms. In a first level analysis, correlations between the BOLD response and emotional condition in each single session were examined at whole brain level. The emotional stimuli were modelled by a square waveform convolved with a gamma func-

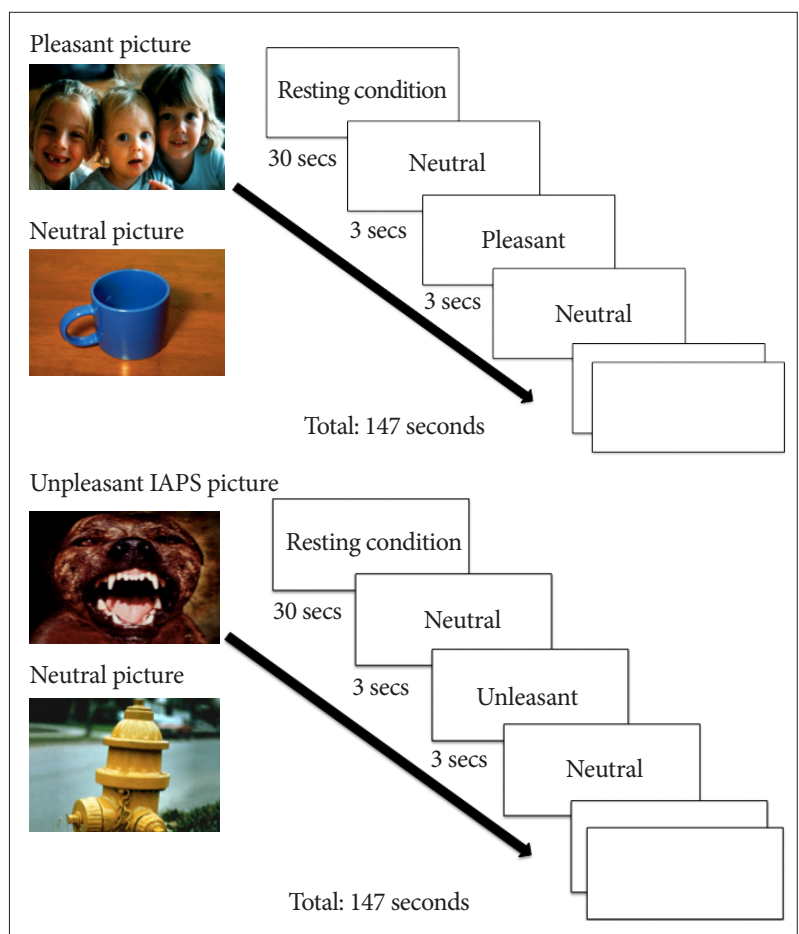

Figure 2. fMRI paradigms. Alternated blocks Neutral/Pleasant (N/ $\mathrm{P})$, Neutral/Unpleasant (N/U). fMRI: functional magnetic resonance imaging, IAPS: the International Affective Picture System. tion plus temporal and dispersion derivatives. The contrasts of interest were pleasant versus neutral and unpleasant versus neutral. In a second level of analysis, results were accumulated across sessions to obtain the mean response for each subject using a FWE-corrected cluster extent threshold $\left(\mathrm{p}_{\mathrm{FWE}}=\right.$ $0.05)$ to correct for multiple comparisons.

2) The second stage involved planned within-group and between-group analyses. Specifically for between group analyses we analysed all ED groups combined compared to controls. We also analysed the subgroups as ED are recognised as phenotypically heterogeneous comprising $\mathrm{AN}, \mathrm{BN}$ and comorbid with BPD groups.

- For each group, a t-test was defined in order to study the mean group effect, that is, if the group activated on average.

- In order to find significant differences between groups, C group was compared with the whole eating disorder group (ED) and each subgroup (AN, BN, EDc) and also subgroups were compared between them. For each comparison, two t-tests were defined to find out, not only the existence of differences between groups, but also the direction of these differences.

3) Finally, on the third stage of analysis, we analysed different Regions of Interest (ROI). For each ROI, we report activations that surpass the uncorrected threshold $\left(\mathrm{p}_{\text {unc }}<0.001\right)$, and at the same time surpass the FWE-corrected cluster extent threshold ( $\mathrm{p}_{\mathrm{FWE}}=0.05$ ) to correct for multiple comparisons.

ROIs were defined using the "Harvard-Oxford Atlas" ${ }^{\text {"55 }}$ and included the amygdala, striatum (caudate and putamen) and parts of prefrontal cortex (PFC) such as the dorsolateral prefrontal cortex (DLPFC), orbitofrontal cortex (OFC), medial prefrontal cortex (MPFC) and frontal pole (FP), areas involved in emotion processing and regulation. ${ }^{6,9,25}$

\section{RESULTS}

Sociodemographic data are summarized in Table 1. There were no significant differences in mean age between the ED as a group compared to controls. Controls were significantly younger on average compared to the AN and EDc groups $(\mathrm{C}<\mathrm{AN}, \mathrm{p}=0.05)$. These differences (all patients and controls ranged between 20 and 40 years) were not considered significant for functional analysis and given the small sample they were not analysed as a covariate.

On average, body mass index in $\mathrm{BN}$ was higher compared to all other three groups, though the greatest difference was found between $\mathrm{AN}$ and $\mathrm{BN}$, as expected.

Education level was similar between eating disorder groups but participants in the healthy control group showed greater educational level compared to $\mathrm{BN}$ and EDc groups. 
Table 1. Demographic variables

\begin{tabular}{lclcccc}
\hline \multicolumn{1}{c}{ Variable } & $\mathrm{AN}(\mathrm{N}=8)$ & $\mathrm{BN}(\mathrm{N}=9)$ & $\mathrm{EDc}(\mathrm{N}=7)$ & $\mathrm{C}(\mathrm{N}=19)$ & $\mathrm{p}$ & Comparison \\
\hline Age, years, Mean (SD) & $30.13(9.25)$ & $28.44(11.21)$ & $32(10.47)$ & $23.18(2.404)$ & 0.05 & $\mathrm{C}<\mathrm{AN} \& \mathrm{EDc}$ \\
BMI, kg/m², Mean (SD) & $16.92(2.80)$ & $25.90(7.54)$ & $19.69(5.13)$ & $19.79(1.54)$ & 0.002 & $\mathrm{BN}>\mathrm{C}, \mathrm{EDc}, \mathrm{AN}$ \\
Education (years) & $15.14(2.54)$ & $14.67(2.44)$ & $13.20(1.78)$ & $16.33(1.41)$ & 0.16 & $\mathrm{C}>\mathrm{EDc} \& \mathrm{BN}$ \\
Barratt & $35(5.31)$ & $52.78(9.92)$ & $63.43(15.38)$ & $33.94(5.76)$ & 0.001 & $\mathrm{EDc}>\mathrm{BN}, \mathrm{AN} \& \mathrm{C}$ \\
BITE & $13.38(8.89)$ & $26.78(6.45)$ & $21.71(7.91)$ & $3.47(3.24)$ & 0.001 & $\mathrm{BN}>\mathrm{EDc}, \mathrm{AN} \& \mathrm{C}$ \\
\hline
\end{tabular}

Age, Body Mass Index (BMI), Education, BITE and Barratt scales according to diagnosis. $\mathrm{p}<0.05$. AN: anorexia nervosa, BN: bulimia nervosa, EDc: eating disorder comorbid with borderline personality disorder, C: control, BITE: Bulimic Investigatory Test, Edinburgh

Table 2. Pleasant paradigm

\begin{tabular}{lcccc}
\hline \multicolumn{1}{c}{ Pleasant-Neutral } & $\mathrm{C}(\mathrm{N}=19)$ & $\mathrm{AN}(\mathrm{N}=8)$ & $\mathrm{BN}(\mathrm{N}=9)$ & \multicolumn{2}{c}{$\mathrm{EDc}(\mathrm{N}=7)$} \\
VMPFC & $\mathrm{p}$ & $\mathrm{p}$ & $\mathrm{p}$ & 0.000208 \\
OFC & 0.000052 & 0.0034 & 0.000094 & 0.000868 \\
Frontal Pole & 0.000025 & 0.000079 & 0.000023 & 0.000208 \\
DLPFC & 0.000015 & 0.000308 & 0.000019 & 0.000872 \\
Left Amygdala & 0.000019 & 0.0011 & 0.000021 & 0.007 \\
Left Caudate & 0.000208 & 0.00012 & 0.000830 & 0.00079 \\
Left Putamen & 0.00026 & 0.00063 & 0.0023 & 0.003 \\
Right Amygdala & 0.00074 & 0.0015 & 0.0029 & 0.006 \\
Right Caudate & 0.000066 & 0.000080 & 0.000303 & 0.010 \\
Right Putamen & 0.000053 & 0.000553 & 0.000775 & 0.019
\end{tabular}

Regions found significantly activated by subgroups and by ROI. Activation=p $<0.05$. ROI: region of interest, MVPFC: ventro medial prefrontal cortex, OFC: orbitofrontal cortex, DLPFC: dorsolateral prefrontal cortex

\section{Pleasant paradigm, within group analysis}

Group activation maps are shown in Table 2. All areas of emotional processing and regulation measured, cortical and subcortical (PFC, amygdala and striatum) were activated in the control group. Similar results were obtained for AN and BN groups excepting the regions: VMPFC and left putamen in AN, left putamen and caudate in BN. EDc did not show activation in the subcortical regions (amygdala, caudate and putamen) except for left caudate, although all prefrontal areas were activated in this group.

\section{Unpleasant paradigm, within group analysis}

Group activation differences are showed in Table 3.

When comparing unpleasant-neutral images between subgroups we found that: control group showed more activation in all selected regions when exposed to unpleasant images compared to neutral ones, except for VMPFC and left putamen. Patients with AN mainly activated DLPFC, FP and left amygdala, while those with $\mathrm{BN}$ and EDc barely activated FP and DLPFC respectively.

\section{Pleasant paradigm, between group analysis}

When comparing the activation between patients as a whole group (all ED subtypes) and controls, no statistically significant differences were found in any of the brain areas selected in this study.

When doing the analysis by subgroups and by ROI, the following differences were found (Table 4 only showing those contrasts that became statistically significant):

- DLPFC was more activated in AN and C compared to $\mathrm{BN}$ and EDc. There was also a tendency towards greater activation of DLPFC in AN versus controls (x: 50.0, y: 34.0, z:12.0; p: 0.0015).

- Left putamen was more activated in control group compared to EDc and in AN compared to EDc.

- FP showed greater activation in AN compared to $\mathrm{BN}$ and $\mathrm{EDc}$, as well as in controls compared to $\mathrm{AN}(\mathrm{C}>\mathrm{AN}>\mathrm{BN}>\mathrm{EDc})$.

Activation maps of more representative results are shown below (Figures 3 and 4). Images from fMRI show brain activation (colored dots) overlaid on a transverse slice of the corresponding structural brain image (grayscale).

\section{Unpleasant paradigm, between group analysis}

During unpleasant paradigm, no statistically significant differences in activation (in any of the brain areas selected) were found when comparing the ED group as a whole (in- 
Table 3. Unpleasant paradigm

\begin{tabular}{|c|c|c|c|c|}
\hline \multirow{2}{*}{ Unpleasant-Neutral } & $\mathrm{C}(\mathrm{N}=19)$ & $\mathrm{AN}(\mathrm{N}=8)$ & $\mathrm{BN}(\mathrm{N}=9)$ & $\operatorname{EDc}(\mathrm{N}=7)$ \\
\hline & $\mathrm{p}$ & $\mathrm{p}$ & $\mathrm{p}$ & $\mathrm{p}$ \\
\hline VMPFC & 0.012 & 0.013 & 0.002 & 0.02 \\
\hline OFC & 0.000158 & 0.0012 & 0.002 & 0.003 \\
\hline Frontal Pole & 0.000168 & 0.000496 & 0.000796 & 0.003 \\
\hline DLPFC & 0.000294 & 0.000102 & 0.002 & 0.00022 \\
\hline Left Amygdala & 0.000765 & 0.003 & 0.007 & 0.011 \\
\hline Left Caudate & 0.000116 & 0,003 & 0.004 & 0.005 \\
\hline Left Putamen & 0.002 & 0,002 & 0.011 & 0.006 \\
\hline Right Amygdala & 0.0010 & 0.000705 & 0.016 & 0.049 \\
\hline Right Caudate & 0.000083 & 0.002 & 0.003 & 0.056 \\
\hline Right Putamen & 0.0010 & 0.001 & 0.01 & 0.081 \\
\hline
\end{tabular}

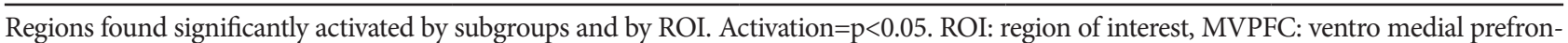
tal cortex, OFC: orbitofrontal cortex, DLPFC: dorsolateral prefrontal cortex

Table 4. Pleasant paradigm

\begin{tabular}{|c|c|c|c|c|c|c|}
\hline \multicolumn{7}{|c|}{ Standard space. montreal neurological institute } \\
\hline ROI & Contrast & $\mathrm{x}$ & $\mathrm{y}$ & $\mathrm{z}$ & $\mathrm{T}$ & Unc. p-value \\
\hline \multirow[t]{4}{*}{ DLPFC } & $\mathrm{AN}>\mathrm{EDc}$ & 50.0 & 38.0 & 12.0 & 4.208 & 0.0008 \\
\hline & $\mathrm{AN}>\mathrm{BN}$ & 46.0 & 36.0 & 14.0 & 4.359 & 0.0005 \\
\hline & $\mathrm{C}>\mathrm{BN}$ & -54 & 10 & 50 & 3.883 & 0.0009 \\
\hline & $\mathrm{C}>\mathrm{EDc}$ & 40 & -6 & 56 & 4.92 & 0.00009 \\
\hline \multirow[t]{2}{*}{ Left Putamen } & $\mathrm{C}>\mathrm{EDc}$ & -26 & -10 & 4 & 4.269 & 0.00043 \\
\hline & $\mathrm{AN}>\mathrm{EDc}$ & -28 & -10 & 4 & 4.59 & 0.0004 \\
\hline \multirow[t]{3}{*}{ Frontal Pole } & $\mathrm{C}>\mathrm{AN}$ & -56 & 38 & 6 & 3.947 & 0.0009 \\
\hline & $\mathrm{AN}>\mathrm{EDc}$ & 50 & 38 & 12 & 4.208 & 0.0008 \\
\hline & $\mathrm{AN}>\mathrm{BN}$ & 46 & 36 & 14 & 4.359 & 0.0005 \\
\hline
\end{tabular}

Group comparisons. Only significant results are shown in this table. Unc. p-value: uncorrected p-value. AN: anorexia nervosa, BN: bulimia nervosa, EDc: eating disorder with comorbid with borderline personality disorder, C: controls, ROI: region of interest, VMPFC: ventromedial prefrontal cortex, OFC: orbitofrontal, Cortex; DLPFC: dorsolateral prefrontal cortex. Voxel size: $2 \times 2 \times 2 \mathrm{~mm}^{3}$

cluding all ED subtypes) with controls.

On analysis the data by subgroups during the unpleasant paradigm, the following significant differences were found (Table 5): greater activation of FP when all patients as a group were compared to controls; greater activation in $\mathrm{AN}$ group when compared to EDc in Orbitofrontal cortex (OFC); greater activation of $\mathrm{FP}$ in $\mathrm{AN}, \mathrm{BN}$ and $\mathrm{EDc}$ when compared to controls and $\mathrm{BN}$ when compared to $\mathrm{AN}$.

Activation maps of more representative results are shown below. Images from fMRI show brain activation (colored dots) overlaid on a transverse slice of the corresponding structural brain image (grayscale) (Figure 5).

\section{DISCUSSION}

The purpose of the present study was to explore the general emotional processing response in $\mathrm{ED}$, in order to develop hypotheses and directions for further research. We hypothesized that an increased emotional reactivity more characteristic of $\mathrm{BN}$ and EDc patients might be a consequence of their inability to adequately engage a reflective -executive system (prefrontal areas) and thus rely heavily upon more automatic response systems (amygdala and basal ganglia). We also hypothesized decreased emotional reactivity and over-control of emotions in AN would be a consequence of hyperactivation of prefrontal brain regions (dorsolateral and orbitofrontal), involved in reflective cortical processing and executive control.

To our knowledge, no previous functional neuroimaging studies have used general emotional stimuli (e.g., IAPS) as a paradigm for emotional processing in ED. ${ }^{56}$ Pictures in IAPS identified as pleasant as well as unpleasant were experienced by participants as stimulating compared to neutral pictures, 


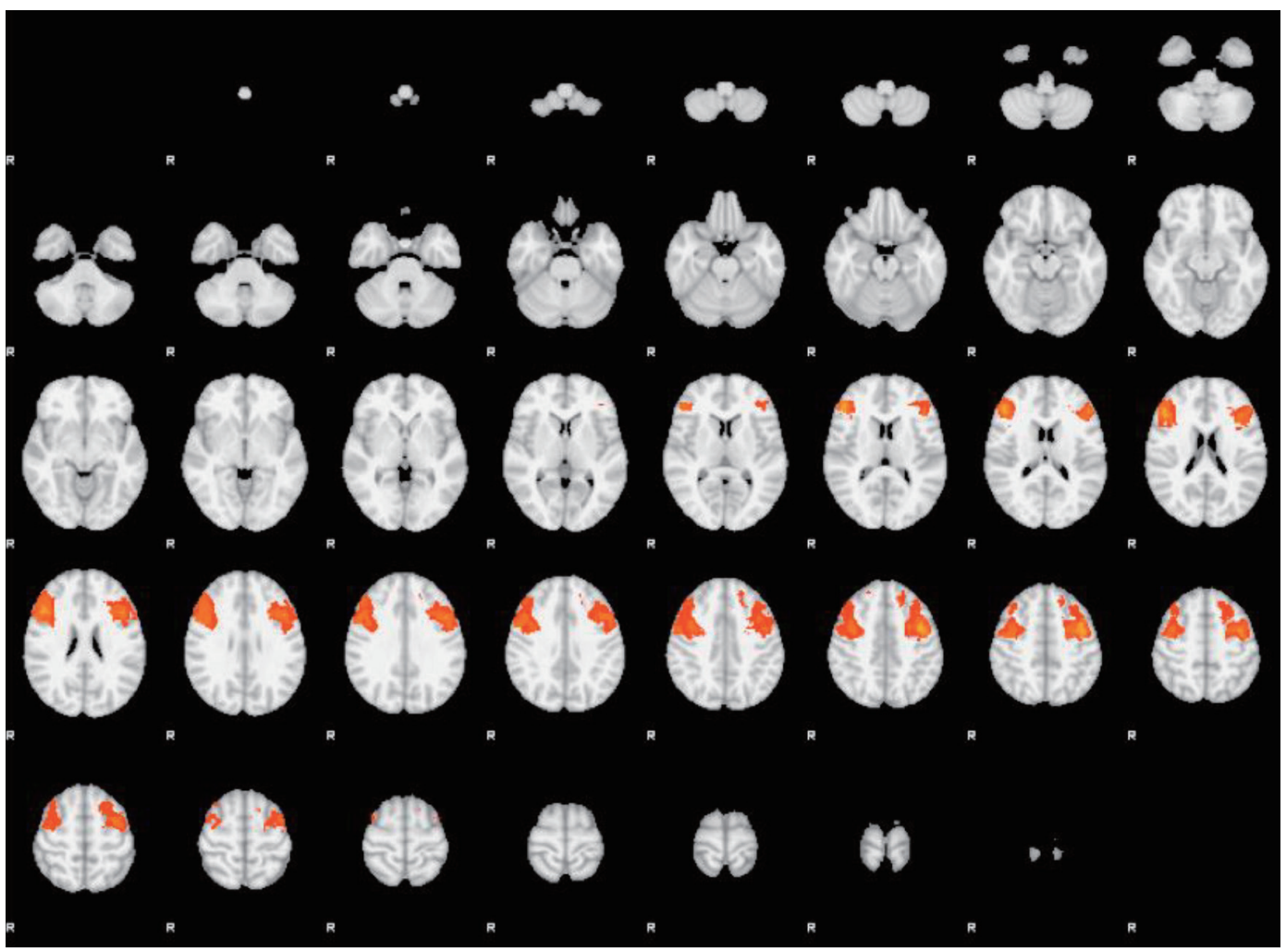

Figure 3. Pleasant stimuli. Dorsolateral Prefrontal Cortex (DLPFC), ROI-based analyses. AN and BN subgroups comparison (AN>BN). Transverse slice. ROI: regions of interest, AN: anorexia; BN: bulimia nervosa.

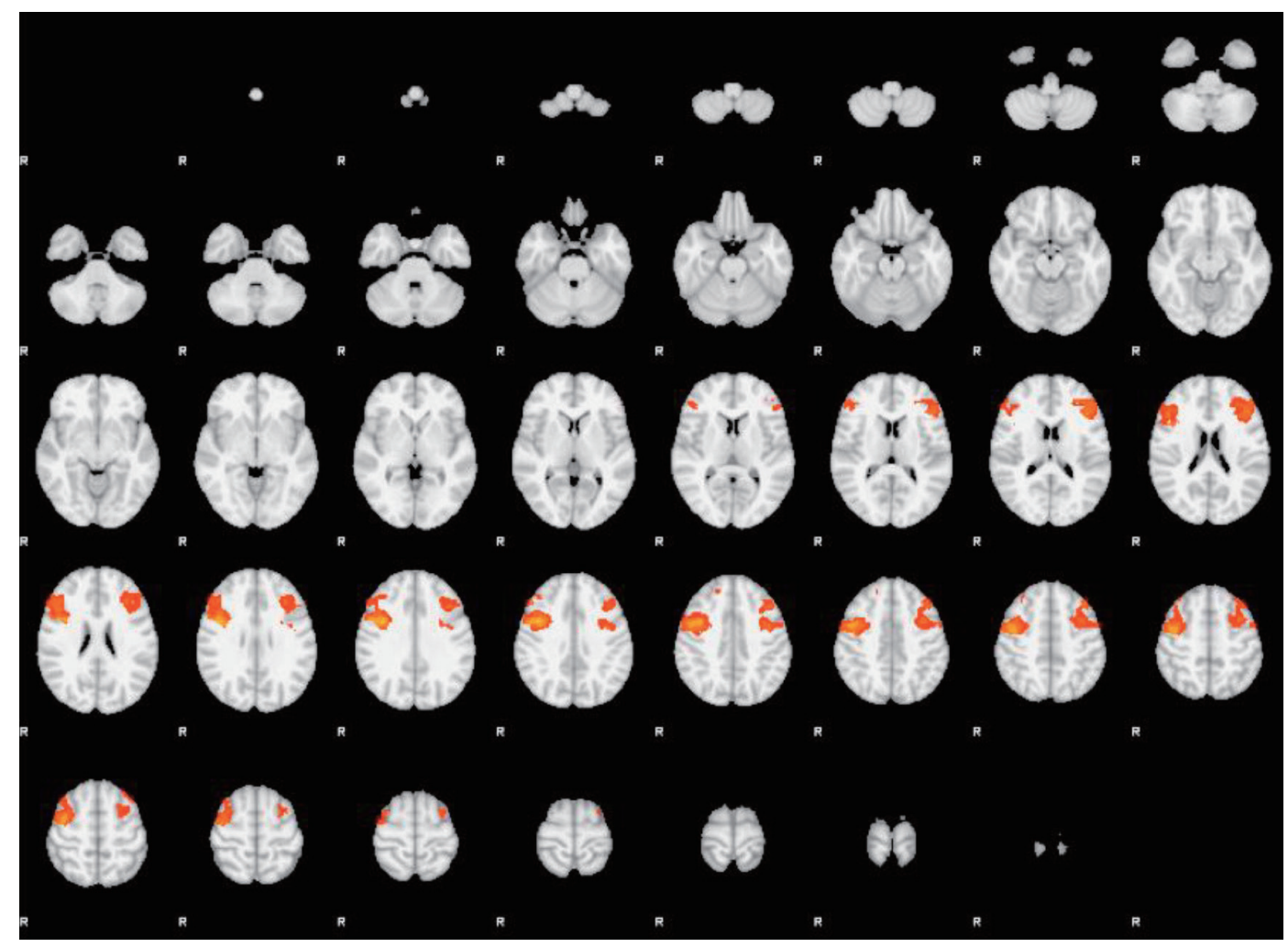

Figure 4. Unpleasant stimuli. Dorsolateral Prefrontal Cortex (DLPFC), ROI-based analyses. C and EDc subgroups comparison (C>EDc). Transverse slice. ROI: regions of interest, C: control, EDc: eating disorder comorbid. 
Table 5. Unpleasant paradigm

\begin{tabular}{lcccccc}
\hline \multicolumn{7}{c}{ Standard space. montreal neurological institute } \\
\hline \multicolumn{1}{c}{ ROI } & Contrast & $\mathrm{x}$ & $\mathrm{y}$ & $\mathrm{z}$ & $\mathrm{T}$ & Unc. p-value \\
\hline OFC & $\mathrm{AN}>\mathrm{EDc}$ & 24.0 & 12.0 & -20 & 4.126 & 0.001 \\
Frontal Pole & $\mathrm{AN}>\mathrm{C}$ & -42 & 64 & 2 & 4.063 & 0.0007 \\
& $\mathrm{BN}>\mathrm{C}$ & -44 & 52 & -10 & 5.027 & 0.00009 \\
& $\mathrm{EDc}>\mathrm{C}$ & -40 & 48 & -6 & 3.938 & 0.0009 \\
& $\mathrm{BN}>\mathrm{AN}$ & 22 & 40 & 14 & 4.192 & 0.0007 \\
\hline
\end{tabular}

Group comparisons. Only significant results are shown in this table. Unc. p-value=uncorrected p-value. AN: anorexia nervosa, BN: bulimia nervosa, EDc: eating disorder with comorbid with borderline personality disorder, C: controls. ROI: region of interest; VMPFC: ventromedial prefrontal cortex, OFC: orbitofrontal cortex, DLPFC: dorsolateral prefrontal cortex. Voxel size: $2 \times 2 \times 2 \mathrm{~mm}^{3}$

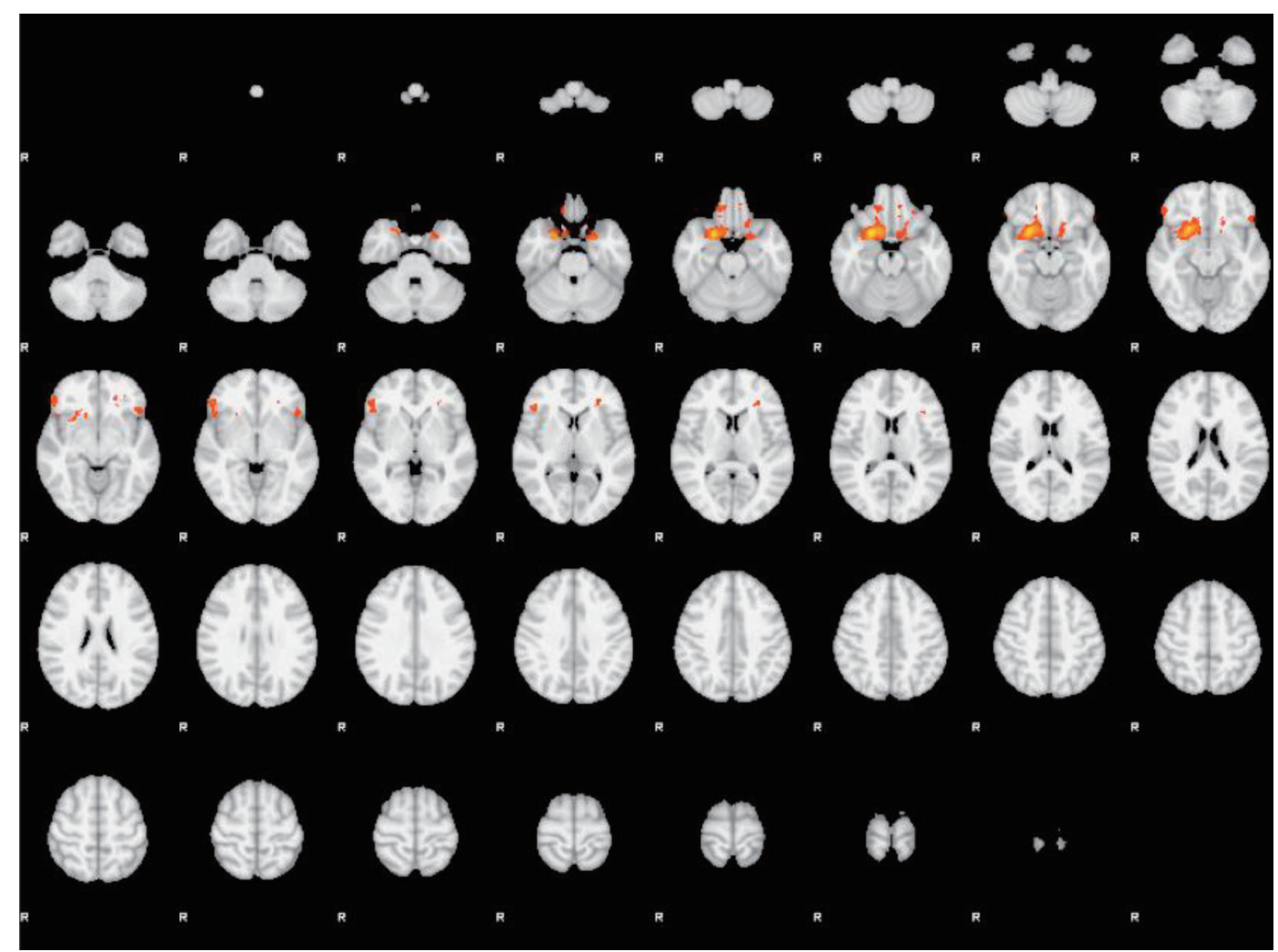

Figure 5. Unpleasant stimuli. Orbitofrontal cortex (OFC), ROI-based analyses. AN and EDc subgroups comparison (AN>EDc). Transverse slice. AN: anorexia nervosa, EDc: eating disorder comorbid.

validating the emotional salience of our paradigm.

Within group analysis examined functional responses to emotionally stimulating stimuli (pleasant or unpleasant versus neutral) for each group of participants. Controls showed increased BOLD responses to both pleasant and unpleasant stimuli compared to neutral ones, in all selected brain regions that have been repeatedly shown to be relevant for emotional processing and regulation: PFC, amygdala and striatum..$^{57-61}$ In contrast, ED subgroups failed to show this default response in some of the selected brain areas (Table 2 and 3). The majority of patient groups showed activation at a cortical level (PFC), lacking subcortical activation (amygdala and striatum), especially during the unpleasant condition. Preliminarily, these results might indicate a difficulty in adequately engaging brain circuits involved in emotional processing in those with EDs.

There may be a number of explanations for a lack of functional activation of subcortical areas in ED groups in general emotional processing:

1) A deficit in the first stage of emotional recognition. However, this explanation contrasts with previous studies that found greater activation in subcortical structures such as 
amygdala in ED patients, ${ }^{36,56}$ which had used specific aversive stimuli (food or body silhouettes).

2) An excessive activation of PFC via "top-down" ${ }^{60,62}$ regulation (cognitive control), that could lead to a relative deactivation of the amygdala and striatum, as it has been shown in previous studies where labelling a stimulus image (e.g., naming the expected affect), resulted in a reduction in amygdala activity. 63,64

3) Finally, a disconnection or desynchronization might exist between cortical structures (PFC) and subcortical regions, as has been seen in BPD patients. ${ }^{65}$

The second phase of analysis included between group comparisons for each specific paradigm (pleasant-neutral and unpleasant-neutral). No differences were found when comparing all combined ED as a group versus controls whether during pleasant or unpleasant paradigm. Since ED include both subgroups of $\mathrm{AN}$ and $\mathrm{BN}$ and EDc (polar opposite groups of what we have hypothesized as the impulsive-compulsive continuum), we infer that it is possible the summation of hypo and hyper-activity from respective ED groups which yields an overall null difference.

Analysis by subgroups during the pleasant paradigm showed greater activation in AN in the DLPFC, frontal pole and left putamen compared to EDc, and a tendency towards greater activation of DLPFC in AN versus controls was also observed. However, these are acknowledged as exploratory findings due to the small subgroup sample size.

The DLPFC is part of the cognitive control network and has been associated with restriction of appetitive responses. ${ }^{66-68}$ Differences found in the DLPFC between AN and EDc and $\mathrm{BN}$ and controls, may be tentatively interpreted in terms of a greater tendency to restrict emotions in AN -through "top-down" mechanisms of PFC inhibiting subcortical structures. $^{12,69-71}$ In partial support of our findings, in BN patients, a deficiency of activation of prefrontal brain regions during appetitive stimuli has been demonstrated. ${ }^{6,28,72,73}$ However, a PET study indicated that regional cerebral blood flow (rCBF) normalized with long-term recovery in $\mathrm{AN}$ and $\mathrm{BN} .{ }^{74}$

Similar results were found in the Frontal Pole (FP) regions (greater activation during the pleasant paradigm in AN compared to $\mathrm{BN}$ and $\mathrm{EDc}$ but not compared to controls).

Taking into account that $\mathrm{BN}$ and $\mathrm{EDc}$ groups showed less activation in the DLPFC when compared to controls, we can therefore suggest there may be a gradient of activation in $\mathrm{PFC}$ regions ( $\mathrm{AN}>\mathrm{C}>\mathrm{BN}>\mathrm{EDc})$.

Moreover, the EDc group showed less activation in left putamen compared to controls and AN, however caudate or amygdala differences did not reach significance compared to other studies. ${ }^{75}$ The striatum (caudate and putamen) is involved in the activation of motor programs (some innate) but also in social-emotional expression, recognition, ${ }^{57,58,76-78}$ and withdrawal behaviours. ${ }^{79}$ Those suffering comorbid BD and BPD have been characterized as showing a lack of emotional control intrinsic to both disorders, in turn related to dysfunction of cortico-striatal circuits. ${ }^{80,81}$ Accordingly, the lower activation of putamen (as a component of corticostriatal circuitry) in these patients might result in an increased anticipatory response when facing emotional stimuli compared to other ED subgroups as well as controls and therefore, a more dysregulated pattern of eating behaviours.

During the unpleasant paradigm the group differences were detected in OFC functional activity. OFC is involved in representing the affective value of reinforcers, decision-making processes, expectation and processing of the negative valence of emotional stimuli. Patients with AN may display excessive control in the compulsive end of the impulsive-compulsive spectrum, while those with BPD have shown frontal dysfunctions, predisposing to lack of control, specifically a disconnection between PFC and limbic areas and reduced frontal inhibitory activity. ${ }^{65}$ Therefore, the greater activation of OFC in AN compared to $\mathrm{EDc}$, suggests that patients with $\mathrm{AN}$ have greater activity in the OFC as exertion of greater cognitive control when facing emotional stimuli. Similar activation results were found in previous studies in AN patients, ${ }^{31}$ however only during presentation of specific disease aversive stimuli (food and silhouettes) and not during general emotional stimuli ${ }^{82}$ as found in this study. In another study using IAPS (emotional perception test in ED), an AN restrictive group showed increased fear when confronted with stimuli containing anger, that was attributed to introversion and conflict avoidance of patients with anorexia. ${ }^{56}$

Overall, our results suggest that there are differential functional patterns emotional processing (e.g., DLPFC) across the groups in our study. Increased DLPFC activity for emotional processing in AN patients might be the basis of excessive top-down regulation: driving excessive emotional control, ruminations about weight, shape and an excessive ability to restrain appetite. Conversely, decreased activation in DLPFC regions to emotional stimuli in $\mathrm{BN}$ and EDc might be the basis of decreased control in eating behaviour and their emotions (Figure 1).

There appears to be differential processing of general emotional stimuli in subgroups of EDs on the basis of hyper or hypo-activity in regions mediating cortical emotional control (such as PFC). These preliminary pilot findings raise the possibility that, when processing emotional cues, persons with AN rely more upon reflective cortical processing and executive control compared to lesser involvement of such processing in those with EDc, BN and controls. These differences in emotional processing activity might thus influence eating 
behaviours. Since these results are regarded as exploratory this should be confirmed in future longitudinal studies.

Our functional emotional processing findings are potentially consistent with the compulsivity to impulsivity continuum model of ED, corresponding to compulsivity of control in $\mathrm{AN}$ and impulsivity of decreased control in $\mathrm{BN}$ and $\mathrm{EDc} .^{83}$ This model of ED also allows a conceptualisation for a bipolar spectrum of emotional processing of ED symptoms over the course of illness (Figure 1) and may potentially have important implications in their classification, treatment and prognosis.

Methodological limitations of this study, which limit generalizability, include: 1) small sample size which limits the power of the study to derive definitive findings, hence our the findings should be regarded as preliminary and exploratory pilot data to help inform future studies; 2) lack of longitudinal follow up in this cross-sectional study; 3 ) conceptual and methodological limitations when trying to study the different components of emotional processing and emotional responsiveness variability; $\left.{ }^{77} 4\right)$ methodological limitations due to fMRI characteristics (e.g., 1.5 tesla MRI against more frequently used 3 tesla MRI); 5) lack of data on severity of psychopathology and pharmacological treatment.

Against these limitations, the strengths of our study must be balanced: the exploratory conceptual advancement of studying general emotional responsiveness developing a hypothetical impulsivity-compulsivity continuum model of $\mathrm{ED}$; distinction of an independent subgroup of EDc allowing a better control of the presence of borderline personality traits in the sample; a priori hypothesis-based stepwise fMRI analysis; and matching of healthy controls on relevant sociodemographic parameters.

In conclusion, differences in functional brain activity in prefrontal areas may help in the phenotypic differentiation of ED subtypes. Our findings provide preliminary exploratory support of a hypothesized pathophysiologic cognitive-control model of ED.

AN patients showed greater activation of areas involved in emotional control (DLPFC) compared to the rest of the groups. These results might be related to a tendency of those with AN to over-control emotions. The control group showed greater activation of DLPFC compared to $\mathrm{BN}$, potentially consistent with the hypothesis of diametrically opposed mechanisms of emotional control among $\mathrm{AN}$ and $\mathrm{BN}$ groups (AN-over-control and BN-deficient control).

In comparison to other diagnostic subgroups, the ED comorbid group $(\mathrm{EDc}=\mathrm{ED}+\mathrm{BPD})$ showed less activation in DLPFC and this might be related to lesser activation of reflective cortical processing areas mediated by the presence of borderline traits.
Overall, differences in activation of PFC areas in ED may potentially represent key functional bases in the general emotional responsiveness of these disorders with implications for their pathophysiologic phenomenology. However, we acknowledge this is a small exploratory pilot study, which will need replication in a larger sample size with investigation of additional regions of interest to see if the findings hold true.

\section{Acknowledgments}

JCLL self-funded travel costs as co-director for RMM-R's PhD (Complutense University) thesis on which this research is based. Ms. Via is supported by an Endeavour Research Fellowship, provided by Australian government, the Department of Education (I.D. 3993_2014). The authors would like to thank all patients and volunteers for their participation in the study and staff at the Psychiatry and Radiology Department of Hospital Clínico San Carlos for their dedicated support.

\section{Conflicts of Interest}

The authors have no potential conflicts of interest to disclose.

\section{Author Contributions}

Conceptualization: Rosa M. Molina Ruiz, Marina Díaz-Marsá, Laura de Anta Tejado, Jose Luis Carrasco Perera. Data curation: Rosa M. Molina Ruiz, Marina Díaz-Marsá, Laura de Anta Tejado, Helena Trebbau López. Formal analysis: T. García-Saíz, M. Rincón Zamorano. Investigation: Rosa M. Molina Ruiz, Marina Díaz-Marsá, Laura de Anta Tejado, Jose Luis Carrasco Perera. Methodology: Rosa M. Molina Ruiz, Marina Díaz-Marsá, Laura de Anta Tejado, Jose Luis Carrasco Perera. Project administration: Rosa M. Molina Ruiz, Marina Díaz-Marsá, Laura de Anta Tejado, Jose Luis Carrasco Perera. Resources: Rosa M. Molina Ruiz, Marina Díaz-Marsá, Laura de Anta Tejado, Jose Luis Carrasco Perera. Software: T. García-Saíz, M. Rincón Zamorano. Supervision: E. Via Virgili, Marina Díaz-Marsá, Jose Luis Carrasco Perera, Jeffrey C.L. Looi. Validation: E. Via Virgili, Marina Díaz-Marsá, Jose Luis Carrasco Perera, Jeffrey C.L. Looi. Visualization: E. Via Virgili, Marina Díaz-Marsá, Jose Luis Carrasco Perera, Jeffrey C.L. Looi. Writing_original draft: Rosa M. Molina Ruiz. Writing-review \& editing: Rosa M. Molina Ruiz, Helena Trebbua López, E. Via Virgili, Marina Díaz-Marsá, Jose Luis Carrasco Perera, Jeffrey C.L. Looi.

\section{ORCID iDs}

Rosa M. Molina-Ruiz

T. García-Saiz

Jeffrey C.L. Looi

E. Via Virgili

M. Rincón Zamorano

Laura de Anta Tejado

Helena Trebbau López

Jose Luis Carrasco Perera

Marina Díaz-Marsá https://orcid.org/0000-0003-1551-2802 https://orcid.org/0000-0002-8321-6274 https://orcid.org/0000-0003-3351-6911 https://orcid.org/0000-0002-2331-3232 https://orcid.org/0000-0002-0138-4662 https://orcid.org/0000-0001-6127-2788 https://orcid.org/0000-0001-8249-8954 https://orcid.org/0000-0003-1481-3574 https://orcid.org/0000-0003-1364-3163

\section{REFERENCES}

1. Brewer R, Cook R, Cardi V, Treasure J, Bird G. Emotion recognition deficits in eating disorders are explained by co-occurring alexithymia. R Soc open Sci 2015;2:140382.

2. Oldershaw A, Hambrook D, Stahl D, Tchanturia K, Treasure J, Schmidt U. The socio-emotional processing stream in Anorexia Nervosa. Neurosci Biobehav Rev 2011;35:970-988.

3. Harrison A, Sullivan S, Tchanturia K, Treasure J. Emotional functioning in eating disorders: attentional bias, emotion recognition and emotion regulation. Psychol Med 2010;40:1887-1897.

4. Espina Eizaguirre A, Ortego Saenz de Cabezón A, Ochoa de Alda I, Joar- 
isti Olariaga L, Juaniz M. Alexithymia and its relationships with anxiety and depression in eating disorders. Pers Individ Dif 2004;36:321-331.

5. Gilboa-schechtman E, Avnon ÃL, Zubery E, Jeczmien P. Emotional processing in eating disorders: specific impairment or general distress related deficiency? Depress Anxiety 2006;23:331-339.

6. Marsh R, Steinglass JE, Gerber AJ, Graziano O'Leary K, Wang Z, Murphy $\mathrm{D}$, et al. Deficient activity in the neural systems that mediate self-regulatory control in bulimia nervosa. Arch Gen Psychiatry 2009;66:51-63.

7. Kelley AE. Ventral striatal control of appetitive motivation: role in ingestive behavior and reward-related learning. Neurosci Biobehav Rev 2004;27:765-776.

8. Kaye WH, Wierenga CE, Bailer UF, Simmons AN, Bischoff-Grethe A. Nothing tastes as good as skinny feels: the neurobiology of anorexia nervosa. Trends Neurosci 2013;36:110-120.

9. Frank GK, Shott ME, Hagman JO, Mittal VA. Alterations in brain structures related to taste reward circuitry in ill and recovered anorexia nervosa and in bulimia nervosa. Am J Psychiatry 2013;170:1152-1160.

10. Wierenga CE, Ely A, Bischoff-Grethe A, Bailer UF, Simmons AN, Kaye WH. Are extremes of consumption in eating disorders related to an altered balance between reward and inhibition? Front Behav Neurosci 2014;8:410.

11. Meyer C, Waller G, Waters A. Emotional States and Bulimic Psychopathology. In: Hoek H, Treasure J, Katzman M, Editors. Neurobiology in the Treatment of Eating Disorders. Chichester: Wiley, 1998, p.271-289.

12. Kaye WH, Fudge JL, Paulus M. New insights into symptoms and neurocircuit function of anorexia nervosa. Nat Rev Neurosci 2009;10:573-584.

13. Waters A, Hill A, Waller G. Bulimics' responses to food cravings: is binge-eating a product of hunger or emotional state? Behav Res Ther 2001;39:877-886.

14. Selby EA, Doyle P, Crosby RD, Wonderlich SA, Engel SG, Mitchell JD, et al. Momentary emotion surrounding bulimic behaviors in women with bulimia nervosa and borderline personality disorder. J Psychiatr Res 2012;46:1492-1500.

15. Lacey JH, Evans CD. The Impulsivist: a multi-impulsive personality disorder. Addiction 1986;81:641-649.

16. Herzog DB, Keller MB, Lavori PW, Kenny GM, Sacks NR. The prevalence of personality disorders in 210 women with eating disorders. J Clin Psychiatry 1992;53:147-152.

17. Skodol AE, Oldham JM, Hyler SE, Kellman HD, Doidge N, Davies M. Comorbidity of DSM-III-R eating disorders and personality disorders. Int J Eat Disord 1993;14:403-416.

18. Koepp W, Schildbach S, Schmager C, Rohner R. Borderline diagnosis and substance abuse in female patients with eating disorders. Int J Eat Disord 1993;14:107-110.

19. Van Velzen LS, Vriend C, de Wit SJ, van den Heuvel OA. Response inhibition and interference control in obsessive-compulsive spectrum disorders. Front Hum Neurosci 2014;8:419.

20. Hollander E, Evers M. Review of obsessive-compulsive spectrum disorders: what do we know? where are we going? Clin Neuropsychiatry J Treat Eval 2004;1:32-51.

21. Skodol AE, Oldham JM. Phenomenology, Differential Diagnosis and Comorbidity of the Impulsive-Compulsive Spectrum Disorders. In: Oldham JM, Hollander E, Editors. Impulsivity and Compulsivity. Washington DC, London: American Psychiatric Press, Inc, 1996, p.1-26.

22. Fineberg NA, Potenza MN, Chamberlain SR, Berlin HA, Menzies L, Bechara A, et al. Probing compulsive and impulsive behaviors, from animal models to endophenotypes: a narrative review. Neuropsychopharmacology 2010;35:591-604.

23. Chamberlain SR, Blackwell AD, Fineberg NA, Robbins TW, Sahakian BJ. The neuropsychology of obsessive compulsive disorder: the importance of failures in cognitive and behavioural inhibition as candidate endophenotypic markers. Neurosci Biobehav Rev 2005;29:399-419.

24. Stein DJ, Lochner C. Obsessive-compulsive spectrum disorders: a multidimensional approach. Psychiatr Clin North Am 2006;29:343-351.

25. Whalen PJ, Rauch SL, Etcoff NL, McInerney SC, Lee MB, Jenike MA.
Masked presentations of emotional facial expressions modulate amygdala activity without explicit knowledge. J Neurosci 1998;18:411-418.

26. Baxter LR. Neuroimaging studies of obsessive compulsive disorder. Psychiatr Clin North Am 1992;15:871-884.

27. Baxter L, Saxena S, Brody A, Ackermann R, Colgan M, Schwartz J, et al. Brain mediation of obsessive-compulsive disorder symptoms: evidence from functional brain imaging studies in the human and nonhuman primate. Semin Clin Neuropsychiatry 1996;1:32-47.

28. Frank GK, Bailer UF, Henry S, Wagner A, Kaye WH. Neuroimaging studies in eating disorders. CNS Spectr 2004;9:539-548.

29. Jáuregui-Lobera I. Neuroimaging in eating disorders. Neuropsychiatr Dis Treat 2011;7:577-584.

30. Ellison ZR, Foong J. Neuroimaging in eating disorders. In: Hoek HW, Treasure J, Melanie A, Editors. Neurobiology in the Treatment of Eating Disorders. West Sussex; John Wiley \& Sons Ltd, 1998, p.255.

31. Wagner A, Matthias R, Dieter B, Schmidt M. Neuronal activity changes and body image distortion in anorexia nervosa. Neuroreport 2003;14: 2193-2197.

32. Uher R, Murphy T, Friederich HC, Dalgleish T, Brammer MJ, Giampietro $\mathrm{V}$, et al. Functional neuroanatomy of body shape perception in healthy and eating-disordered women. Biol Psychiatry 2005;58:990-997.

33. Fladung AK, Grön G, Grammer K, Herrnberger B, Schilly E, Grasteit $\mathrm{S}$, et al. A neural signature of anorexia nervosa in the ventral striatal reward system. Am J Psychiatry 2010;167:206-212.

34. Miyake Y, Okamoto Y, Onoda K, Shirao N, Okamoto Y, Otagaki Y, et al. Neural processing of negative word stimuli concerning body image in patients with eating disorders: an fMRI study. Neuroimage 2010;50: 1333-1339.

35. Vocks S, Busch M, Grönemeyer D, Schulte D, Herpertz S, Suchan B. Neural correlates of viewing photographs of one's own body and another woman's body in anorexia and bulimia nervosa: an fMRI study. J Psychiatry Neurosci 2010;35:163-176.

36. Seeger G, Braus DF, Ruf M, Goldberger U, Schmidt MH. Body image distortion reveals amygdala activation in patients with anorexia nervosa -a functional magnetic resonance imaging study. Neurosci Lett 2002;326:25-28.

37. Sachdev P, Mondraty N, Wen W, Gulliford K. Brains of anorexia nervosa patients process self-images differently from non-self-images: an fMRI study. Neuropsychologia 2008;46:2161-2168.

38. Gizewski E, Rosenberger C, de Greiff A, Moll A, Senf W, Wanke I, et al. Influence of satiety and subjective valence rating on cerebral activation patterns in response to visual stimulation with high-calorie stimuli among restrictive anorectic and control women. Neuropsychobiology 2010;62:182-192.

39. Esposito R, Cieri F, di Giannantonio M, Tartaro A. The role of body image and self-perception in anorexia nervosa: the neuroimaging perspective. J Neuropsychol 2018;12:41-52.

40. Spangler DL, Allen MD. An fMRI investigation of emotional processing of body shape in bulimia nervosa. Int J Eat Disord 2012;45:17-25.

41. Lang PJ, Bradley MM, Cuthbert BN. International Affective Pictures System (IAPS): Technical Manual and Affective Ratings. Gainesville, FL: NIMH Cent Study Emot Attention, University of Florida; 2001.

42. Tapajóz P, de Sampaio F, Soneira S, Aulicino A, Harris P, Allegri R. Emotional reactivity to social stimuli in patients with eating disorders. Psychiatry Res 2015;229:887-894.

43. Northoff G, Richter A, Gessner M, Schlagenhauf F, Fell J, Baumgart F, et al. Functional dissociation between medial and lateral prefrontal cortical spatiotemporal activation in negative and positive emotions: a combined fMRI/MEG study. Cereb Cortex 2000;10:93-107.

44. Takahashi H, Koeda M, Oda K, Matsuda T, Matsushima E, Matsuura $\mathrm{M}$, et al. An fMRI study of differential neural response to affective pictures in schizophrenia. Neuroimage 2004;22:1247-1254.

45. Britton JC, Phan KL, Taylor SF, Welsh RC, Berridge KC, Liberzon I. Neural correlates of social and nonsocial emotions: An fMRI study. Neuroimage 2006;31:397-409. 
46. Grimm S, Schmidt CF, Bermpohl F, Heinzel A, Dahlem Y, Wyss M, et al. Segregated neural representation of distinct emotion dimensions in the prefrontal cortex-an fMRI study. Neuroimage 2006;30:325-340.

47. Berlin HA, Rolls ET, Iversen SD. Borderline personality disorder, impulsivity, and the orbitofrontal cortex. Am J Psychiatry 2005;162:2360-2373.

48. American Psychiatric Association. Diagnostic and Statistical Manual of Mental Disorders (DSM-IV). 4th Ed. Washington, DC.: American Psychiatry Press; 2000

49. Spitzer RL, Williams JB, Gibbon M, First MB. The Structured Clinical Interview for DSM-III-R (SCID). I: History, rationale, and description. Arch Gen Psychiatry 1992;49:624-629.

50. Patton JH, Stanford MS, Barratt ES. Factor structure of the Barratt impulsiveness scale. J Clin Psychol 1995;51:768-774.

51. Orozco-Cabal L, Rodríguez M, Herin DV, Gempeler J, Uribe M. Validity and Reliability of the Abbreviated Barratt Impulsiveness Scale in Spanish (BIS-15S). Rev Colomb Psiquiatr 2010;39:93-109.

52. Henderson M, Freeman CP. A self-rating scale for bulimia: The "BITE." Br J Psychiatry 1987;150:18-24.

53. Rivas T, Bersabé R, Jiménez M. Reliability and validity of Bulimic Investigatory Test, Edinburgh (BITE)-Behavioral Psychology / Psicología Conductual. Behav Psychol 2004;12:447-461.

54. Jayaro C, de la Vega I, Díaz-Marsá M, Montes A, Carrasco JL. The use of the International Affective Picture System for the study of affective dysregulation in mental disorders. Actas españolas Psiquiatr 2008;36:177182 .

55. Desikan RS, Ségonne F, Fischl B, Quinn BT, Dickerson BC, Blacker D, et al. An automated labeling system for subdividing the human cerebral cortex on MRI scans into gyral based regions of interest. Neuroimage 2006;31:968-980.

56. Joos AA, Saum B, van Elst LT, Perlov E, Glauche V, Hartmann A, et al. Amygdala hyperreactivity in restrictive anorexia nervosa. Psychiatry Res 2011;191:189-195.

57. Adolphs R. Neural systems for recognizing emotion. Curr Opin Neurobiol 2002;12:169-177.

58. Cancelliere AE, Kertesz A. Lesion localization in acquired deficits of emotional expression and comprehension. Brain Cogn 1990;13:133147.

59. Davidson R, Irwin W. The functional neuroanatomy of emotion and affective style. Trends Cogn Sci 1999;3:11-21.

60. Ochsner KN, Gross JJ. The cognitive control of emotion. Trends Cogn Sci 2005;9:242-249.

61. Vuilleumier P. How brains beware: neural mechanisms of emotional attention. Trends Cogn Sci 2005;9:585-594.

62. Banks SJ, Eddy KT, Angstadt M, Nathan PJ, Phan KL. Amygdala-frontal connectivity during emotion regulation. Soc Cogn Affect Neurosci 2007;2:303-312.

63. Hariri AR, Bookheimer SY, Mazziotta JC. Modulating emotional responses: effects of a neocortical network on the limbic system. Neuroreport 2000;11:43-48.

64. Lieberman MD, Eisenberger NI, Crockett MJ, Tom SM, Pfeifer JH, Way BM. Putting feelings into words: affect labeling disrupts amygdala activity in response to affective stimuli. Psychol Sci 2007;18:421-428.

65. New AS, Hazlett EA, Buchsbaum MS, Goodman M, Mitelman SA, Newmark R, et al. Amygdala-prefrontal disconnection in borderline personality disorder. Neuropsychopharmacology 2007;32:1629-1640.
66. Val-Laillet D, Aarts E, Weber B, Ferrari M, Quaresima V, Stoeckel LE, et al. Neuroimaging and neuromodulation approaches to study eating behavior and prevent and treat eating disorders and obesity. NeuroImage Clin 2015;8:1-31.

67. Geller J, Cockell SJ, Hewitt PL, Goldner EM, Flett GL. Inhibited expression of negative emotions and interpersonal orientation in anorexia nervosa. Int J Eat Disord 2000;28:8-19.

68. Schlösser RGM, Wagner G, Schachtzabel C, Peikert G, Koch K, Reichenbach JR, et al. Fronto-cingulate effective connectivity in obsessive compulsive disorder: a study with fMRI and dynamic causal modeling. Hum Brain Mapp 2010;31:1834-1850.

69. Van Kuyck K, Gérard N, Van Laere K, Casteels C, Pieters G, Gabriëls L, et al. Towards a neurocircuitry in anorexia nervosa: evidence from functional neuroimaging studies. J Psychiatr Res 2009;43:1133-1145.

70. Zastrow A, Kaiser S, Stippich C, Walther S, Herzog W, Tchanturia K, et al. Neural correlates of impaired cognitive-behavioral flexibility in anorexia nervosa. Am J Psychiatry 2009;166:608-616.

71. Adan W, Kaye WH. Behavioral Neurobiology of Eating Disorders. Berlin: Springer; 2011.

72. Klump KL, Strober M, Bulik CM, Thornton L, Johnson C, Devlin B, et al. Personality characteristics of women before and after recovery from an eating disorder. Psychol Med 2004;34:1407-1418.

73. Uher R, Murphy T, Brammer MJ, Dalgleish T, Phillips ML, Ng VW, et al. Medial prefrontal cortex activity associated with symptom provocation in eating disorders. Am J Psychiatry 2004;161:1238-1246.

74. Guido KWF, Bailer UF, Meltzer CC, Price JC, Mathis CA, Wagner A, et al. Regional cerebral blood flow after recovery from anorexia or bulimia nervosa. Int J Eat Disord 2007;40:488-492.

75. Koenigsberg HW, Siever LJ, Lee H, Pizzarello S, New AS, Goodman M, et al. Neural correlates of emotion processing in borderline personality disorder. Psychiatry Res 2009;172:192-199.

76. Calder AJ, Keane J, Manes F, Antoun N, Young AW. Impaired recognition and experience of disgust following brain injury. Nat Neurosci 2000;3:1077-1078.

77. Canli T, Zhao Z, Desmond JE, Kang E, Gross J. An fMRI study of personality. Behav Neurosci 2001;115:33-42.

78. Pell MD, Leonard CL. Processing emotional tone from speech in Parkinson's disease: a role for the basal ganglia. Cogn Affect Behav Neurosci 2003;3:275-288.

79. Grillner S, Hellgren J, Ménard A, Saitoh K, Wikström MA. Mechanisms for selection of basic motor programs--roles for the striatum and pallidum. Trends Neurosci 2005;28:364-370.

80. Bohon C, Stice E. Reward abnormalities among women with full and subthreshold bulimia nervosa: a functional magnetic resonance imaging study. Int J Eat Disord 2011;44:585-595.

81. Wagner A, Aizenstein H, Venkatraman VK, Bischoff-Grethe A, Fudge J, May JC, et al. Altered striatal response to reward in bulimia nervosa after recovery. Int J Eat Disord 2010;43:289-294.

82. Uher R, Brammer MJ, Murphy T, Campbell IC, Ng VW, Williams SCR, et al. Recovery and chronicity in anorexia nervosa: brain activity associated with differential outcomes. Biol Psychiatry 2003;54:934942.

83. Allen A, King A, Hollander E. Obsessive-compulsive spectrum disorders. Dialogues Clin Neurosci 2003;5:259-271. 